\title{
ESL Teacher Education and Intercultural Communication: Discomfort as a Learning Tool
}

Ruth Johnson

This article reports on a simulation used in a course in intercultural communication in an ESL/EFL teacher education program at Southern Illinois University at Carbondale. The simulation was designed to create an unfamiliar and uncomfortable atmosphere, culturally, for the students, similar to what one would experience were he or she in a foreign environment. For three weeks of the semester the students were required to greet one another at the opening and closing of class in a particular manner, modeled after the greetings used in the Yoruba (West Africa) culture. The focus of the simulation was at the affective level, to help students recognize themselves as cultural beings whose cultural beliefs would influence the learning process of their own students. Also reported are excerpts from students' journals and students' evaluations of the simulation.

Those of us who have lived abroad know that when we are immersed in a "foreign" culture awareness of the new culture tends to come over time. However, even living in another culture does not ensure that one will become more aware culturally. When I taught a course in intercultural communication, one man in my class said he survived working in Japan for over a year by remembering that "American is better" and "I'll be here for only a little while." International students in my class echoed the latter statement, saying they survived their educational experience in the United States by reminding themselves that the condition was not permanent.

A more complex issue facing ESL teachers relates to multicultural classes. ESL teachers should acquire empathy for others' cultural behaviors and beliefs. This, I suggest, is done in part through awareness of oneself as a cultural being.

Lewald (1968) puts it this way: "What has to happen in the mind of a boy from Kansas to make him react like an Italian when facing a teacher, a companion, or a girl?" The question remains valid today.

The person who can accomplish this feat may be said to be an intercultural communicator. Students of applied linguistics are taught that language and culture are intertwined. For teacher trainers, the challenge is to educate novice teachers in training in how-to methods for teaching culture with language. Often ESL/EFL teachers do not take into account the fact that they 
themselves are cultural beings whose cultural beliefs influence, positively or negatively, the learning process.

Part of the problem is that not enough is known about what cultural content to teach. In a study involving Nigerian students, Boski (1988) offered the in-group favoritism hypothesis in which emotional or interpersonal dimensions are important for ethnic (cultural) self-identity whereas, in contrast, in-group members are viewed as rivals, even threats, in achievementrelated performance. It would be important for the intercultural communicator to know if this phenomenon operates for (all) other culture groups in order to determine the effect such emotional versus achievement behavior has on classroom interaction.

Brislin (1978) identified negative out-group emotional reactions as prejudice, noting that

one of the most amazing facts about a culture is that it can socialize its members into believing that their culture has the one correct set of behaviors for all situations which a person is likely to encounter. (p. 33)

Prejudices are formed through more than cognitive avenues; that is, through more than what one learns. Prejudices may be formed, say, to please one's parents or to express how one feels about oneself. Cushner (1988) contends that

an intercultural ... perspective does not come automatically with cognitive development or physical maturity; certain experiences at specific times in one's development are critical to attitude and knowledge formation. (p. 161)

He notes that preparing people for intercultural interactions is difficult, complicated by the fact that individuals often have had little interaction with people from other cultures and have made little effort to reflect on their own experience.

Brislin (1978) says that programs that focus only on the cognitive factor fail because other (and stronger) factors are not addressed. Both he and Cushner (1988) propose programs that, in addition to cognitive training, stress self-awareness, explanations of behavior from the point of view of people in other cultures, behavior modification, and experiential learning, in which people "actively participate in realistic simulations of other cultures" (p. 42).

Prior to the training, Mantle-Bromley (1992) argues, there is a need to teach students how to revise their cultural patterns, which involves their attitudes, readiness, and self-awareness, in conjunction with the process of acculturation. Attitude includes acceptance by the learner that the target cultural event is "an alternative behavior, rather than a 'wrong' behavior" ( $p$. 118). Readiness is achieved by having students participate "in activities that 
[are] designed to help them accept the frustration and ambiguity that is inherent in acculturation" (p. 119) whereas self-awareness serves as "the core of a program of attitude readiness" (p. 119).

"Simply being in an intercultural situation will not automatically bring about enhanced intercultural understanding," Rash (1988) contends. Rather, an intercultural situation may result in discomfort because the assumptions on which one bases one's behavior are challenged. The goal, Rash says, is not change per se but the integration of oneself into a different cultural situation without losing one's own identity; one must strive "to hold two apparently or really inimical viewpoints in mind at the same time, allowing both the right to exist" (p. 215).

To achieve the goal of intercultural communication in the ESL/EFL classroom, teachers must be intercultural communicators themselves, aware of their own cultural experiences, able to learn from another culture, and committed to teaching others how to communicate across cultures (Ernst, 1993). Simulations are effective in intercultural training if they focus on commonalities. However, Zevin (1993) objects to the compression of factual information about other cultures as presented in "global studies" classes or intercultural communication classes because the result often is a creation of distance between the students and the cultures being studied, leading to a view of the foreign culture as other, strange, exotic, and incomprehensible. Rash (1988) argues that

Dialogue becomes possible when each side begins to experience the minimizing of differences-not the forgetting of differences, but the sense that there exists another if not a broader perspective, a realm of shared values. (p. 222)

Clavijo (1984) suggests that the realization of commonalities can be achieved through culture-specific instruction: to present unique behaviors of another culture while at the same time explaining to students where the commonality lies. Thus, for example, although eating behaviors vary from culture to culture, the fact that all people eat and have rules for eating is common. Culture-specific instruction coupled with culture-universal awareness can raise students' "perception of similarities between one's own culture and the target culture" (p. 90) and enhance intercultural communication.

This article describes an assignment in a graduate level intercultural communication class that was designed to help students experience and understand communication across cultures by focusing on a culture-specific behavior that is based on a culture-universal function-greetings. There were 12 students in this class, seven women (two each from the US and Korea and one each from Taiwan, Turkey, and Costa Rica) and six men (five from the US and one from Japan), all of whom were under the age of 30 
except for one man in his late 50s. The course is an elective in the Southern Illinois University TESOL master's program and focuses mainly on helping students understand what to expect in the ESL classroom situation vis-à-vis various cultures and how to handle the unfamiliar.

For this assignment, I wanted to involve my students in a simulation that would be an integral part of the class and would last over time. It had to be an assignment that "requested behavior that is inconsistent with one's attitudes" (Mantle-Bromley, 1992, p. 124).

From the recommendations found in the literature, I wanted this experience to have the following components:

1. a simulation in which students felt discomfort because this is one of the feelings most often identified by people going through culture shock;

2. an environment in which the students were required to participate and to reflect on the external behavior and their internal feelings in the context of themselves as cultural beings;

3. a setting in which the students could choose to not participate any longer so that, at the point when negative feelings would presumably be highest, each would have the opportunity to leave an uncomfortable situation and cognitively reflect on the reasons why she or he wanted to do so and what that decision would mean in a real setting.

The greeting activity I selected met the above criteria in these ways:

1. the form of the greeting chosen was strange to everyone in the class to encourage feelings of discomfort;

2. students were required to participate daily, with one exception (see 3), and were required to write a weekly journal entry regarding their reactions;

3. students were free to stop participating in the greeting ritual whenever their discomfort became too great; at that point, they were required to write a reflection paper in which they outlined why they stopped and what this decision would mean if they were in a real situation where such behavior was mandatory.

Thus the rationale for introducing the greeting ritual was to raise the level of the students' awareness of themselves as cultural beings by causing the discomfort that is felt when we actually do immerse ourselves in a foreign culture and by having them reflect on their feelings in a personal way.

What follows is a description of the Yoruba (from western Nigeria) greeting as I adapted it to my classroom and the reactions of my students.

First, the students were arranged in order, based on age and gender. Then the eldest male and I sat together in the center of a circle and each person greeted us in a particular way based on his or her position in the culture. Younger females had to kneel before the two of us; older females had to curtsy; young males had to prostrate (a position loosely resembling a pushup); older males bowed and touched their right foot. Young females curtsied 
to the older males and females, and the young males bowed to the older males and females. The process was repeated as a closing.

During the three weeks that we lived in this culture, I added new behaviors here and there: the elder would place his hands on the heads of the younger ones when they said Good morning; the younger members were instructed not to look into the eyes of the elders; the elders were given responsibility for instructing the younger ones when the latter did not follow the prescribed behavior.

The results of the contrived greeting were astounding. At the outset, there was a lot of laughter when people greeted one another. Within three class periods, however, students were reminding each other about the greeting and how to do it correctly.

Mary, you forgot to greet "Baba" and "Mama."

Look at Richard. He really knows how to prostrate; he should teach the others.

Students were being transformed into members of this culture without instruction beyond the initial how-to demonstration; acculturation was taking place. There was also a lot of discomfort. One example was an incident involving two female students outside the class, which illustrates that although the behavior was accepted or at least tolerated inside the classroom, it was not acceptable outside. One student wrote in her journal that a second student had addressed her as "Auntie" in the student lounge (this is the name younger males and females were to call the older females). She said:

I don't want her to call me "Auntie" outside of the class. I am not much older than she-not old enough to be her aunt and I am not her blood relative. I don't like this situation.

The culture shock process, including feelings toward the novelty of the situation, anger, and then acceptance did take place among several of the students, as evidenced by their journal entries in which they revealed the process of change they underwent. The "strange" becoming the "familiar" is important in intercultural communication education because, as outlined by Mantle-Bromley (1992), it is not the outside activity that changes, but the person's attitude toward it. This attitude change is a large part of becoming aware of oneself as a cultural being.

At the beginning, I did not feel any hard feelings like hatred or disgust or boredom. But towards the middle, I could trace feelings in me whenever I had to greet [Baba and Mama].

It became a humiliating experience.

Later, I was getting used to it. 
I was surprised that I felt so strongly about greeting my classmates and teacher the way that we had to. It felt strange.

I was ready to drop out. To curtsy before a fellow student who was called "Baba" was too threatening for me. It reminded me of my authoritarian father.

Others wrote expressly about the contrived nature of the classroom ritual, and they speculated on their reactions if this type of greeting were expected of them in a real culture. They were becoming aware of themselves as cultural beings. As noted by Cushner (1988), the ability to be aware of one's feelings and then analyze them in a classroom situation is what makes learning intercultural communication possible. The students wrote:

I realized that some parts of the performances were difficult to do.... This gave me a clue about my attitude in coping with new and different situations.... As the days began to pass by and there were no changes toward the situation, I began to feel familiar with it, and I took it as something else I had to do.

I didn't find the situation to be too bad or intolerable since it stopped as soon as class finished. Had it been a nonstop situation, I would have gotten annoyed and tired of it quite soon.

I didn't mind doing this because I kept reminding myself that it was only temporary. But if I had to greet people in that way, in reality, I know I could not do it.

I can say that it didn't take me long to adjust to the situation. At first, I was a little taken aback, but then when everyone else was doing something, it seemed less threatening.

Several students noted in their journals that the exercise took too long to do each day and that it detracted from "real" classroom activities. A typical comment was "I got bored. It took up too much time. I kept wanting to get into the real thing."

In fact the entire greeting at the beginning and closing of each class period took a total of about five minutes. It wasn't the duration of the ritual that was a problem to my students; it was their discomfort. Real classroom activities to them were discussions about cultural issues such as culture shock and acculturation. In other words, they identified much more strongly with intellectualizing their learning than they did with feeling it. But the learning was going on in the feeling and in my students' awareness of their feelings. Eventually (after about three weeks), the discomfort level was so high that all of the students opted to suspend the greeting ritual.

Two students were instructed to devise another greeting ritual, but the class members voted against it. Clearly the greeting ritual had achieved 
something, and I think that something was awareness of themselves in a foreign situation-what they could tolerate and what they could not.

Two months after this experience (at the close of the class) several students commented specifically on the classroom ritual as a learning experience:

It helped me a lot in raising my own consciousness ... as a human being and a cultural being.

I appreciated what was done in this class (in reference to the classroom ritual) to help each student learn.

The activity and the extensive "free" writing was the most helpful part of this course.

My world view (was) expanded ... a great deal [as a result of the greeting ritual].

I learned to think and question myself and my culture and my views.

I was stimulated to think deeply.

This was a useful experience. I have learned a lot ... that will help me ... as a teacher in the future.

What was most helpful about the course was that through the greeting activity I had to learn that I have to know myself first before I can know others.

I reminded the students that initially intolerable behaviors such as the greeting ritual are what sojourners such as ESL students discover in other cultures.

One cannot be exposed, even intellectually, to all aspects of another culture prior to living in that culture. Single-topic assignments may not predict how a student would operate if placed in that culture. What is valuable about the exercise outlined in this article is that the particular behavior to be performed by the students is not the important element; their reactions are. The exercise can be adapted to include any type of behavior as long as the criteria outlined above are followed. In fact, I used an adaptation of this assignment in another intercultural communication class that involved a "foreign" way of turn-taking in classroom discussion. The behavior was the avenue for learning; the students' discomfort with the turn-taking ritual and their reactions to it (similar to the greeting ritual discussed in this article) were the learning.

What does one do when committed to a teaching contract in a culture whose members manifest unfamiliar behaviors, behaviors that the foreigner is expected to adhere to? It is in this aspect that one can challenge oneself to 
be aware of oneself as a cultural being, not to place oneself in situations that are completely intolerable, and to be more accepting of "strange" behavior.

\section{Note}

All excerpts are used with permission.

\section{Acknowledgments}

The author would like to thank Drs. P. Angelis, L. Rosow, K. Wilhelm, and Ms. R. Moore for their comments on earlier versions.

\section{The Author}

Ruth Johnson is an assistant professor of applied linguistics/TESOL in the Department of Linguistics, Southern Illinois University at Carbondale. Her research interests include investigating ways of teaching intercultural communication in the ESL classroom more effectively, understanding student teachers' conceptions of themselves as teachers, and researching the perceptions native speakers of English have of nonnative speakers of English due to the latters' "accent."

\section{References}

Boski, P. (1988). Cross-cultural studies of person perception. Journal of Cross-cultural Psychology, 19(3), 287-328.

Brislin, R.W. (1978). Structured approaches to dealing with prejudice and intercultural understanding. International Journal of Group Tensions, 8, 33-47.

Clavijo, F.J. (1984). Effects of teaching culture on attitude change. Hispania, 67(1), 88-91.

Cushner, K. (1988). Achieving intercultural effectiveness: Current knowledge, goals and practices. Education and Urban Society, 20(2), 159-176.

Ernst, G. (1993, April). Mirrors of difference: Critical perspectives of bilingual/ESL and mainstream teachers on pedagogy, language, and culture (Report No. CS-580-337). Atlanta, GA: Annual Meeting of the American Educational Research Association. (ERIC Document Reproduction Service No. 361823 )

Lewald, H.E. (1968). A tentative outline in the knowledge, understanding, and teaching of cultures pertaining to the target language. Modern Language Journal, 52, 301-309.

Mantle-Bromley, C. (1992). Preparing students for meaningful culture learning. Foreign Language Annals, 25(2), 117-127.

Rash, J.E. (1988). Practical perspectives on intercultural understanding. Education and Urban Society, 20(2), 211-225.

Zevin, J. (1993). World studies in secondary schools and the undermining of ethnocentrism. The Social Studies, 84(4), 82-86. 